\title{
Materials with Memory Shape Effect. Heating Speed - Response Speed
}

\section{Glushchenkov, V. Alekhina, and R. Bikbaev}

Samara University, 443086, Russia, Samara, Moskovskoye Shosse, 34

\section{Abstract}

The material with memory of shape - nitinol - is used in technique as an actuator in various devices of deforming, testing as well as in servo mechanisms. An important characteristic of such actuators is the rate of development of stresses. As a rule, the rod constructions are used in these actuators as power elements. But their use has limitations associated with the need to ensure rapid and uniform over the cross section heating them as well as with difficulties of methodological nature to create "shape memory".

Corresponding Author: Vladimir Glushenkov vgl@ssau.ru

Received: 21 December 2017

Accepted: 15 April 2018

Published: 6 May 2018

Publishing services provided by Knowledge E

(c) V. Glushchenkov et al. This article is distributed under the terms of the

Attribution License, which permits unrestricted use and redistribution provided that the original author and source are credited.

Selection and Peer-review under the responsibility of the MIE-2017 Conference Committee.

\section{G OPEN ACCESS}

\section{INTRODUCTION}

Materials with "memory of shape" find application in medicine and technology [1-3]. Among of all "shape- memory" alloys, of greatest interest is the alloy of titanium with nickel ( $\mathrm{NiTi}$ - nitinol as the alloy that develops reasonable large stresses during reverse martensitic transformation at predetermined, even though limited, displacements [45]. In engineering the choice of nitinol is primarily due to the need to create a different kind of deforming tool, appliances, equipment, for examples, presses, presses-dies for implementation of dividing operations, durometers for special applications with small mass-overall dimensions and low power consumption, devices for use by the emergencies Ministry and others [6-8]. (Figure 1).

All known devices use power elements of rod structures as actuators [8]. But such power elements have some shortcomings: reducing their efficiency as a result of the non-uniformity of temperature fields in the cross section of the rod, methodological difficulties of creating "memory" (the use of equipment developing large stresses to induce memory), low productivity due to significant time of heating and cooling of the 
rod element in multi-cycle use, the complexity of the supply and removal of heat, high energy consumption in this case. Studies of the authors are directed at solving the above problems.

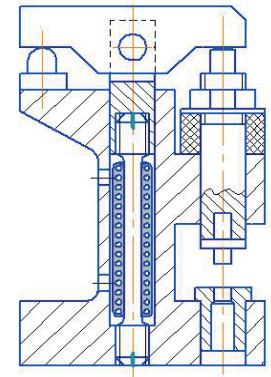

a)

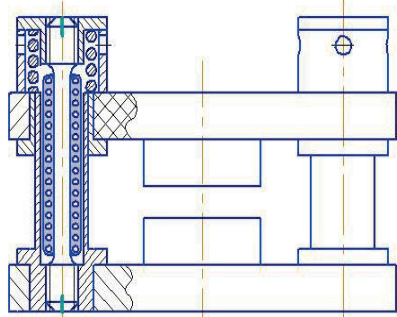

b)

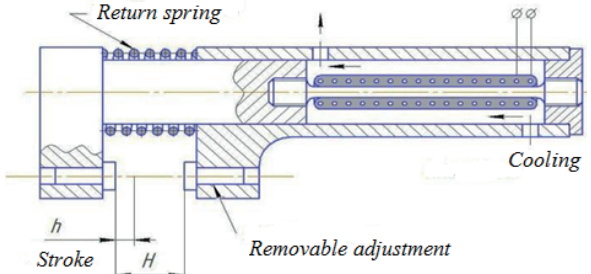

c)

Figure 1: Examples of devices with rod actuators from the shape-memory material. a) press; b) press-die; c) durometer.

It is proposed to replace the rod power element by the multi-link design, consisting of thermally thin bodies, e.g. wires $\varnothing 1-\varnothing 1,5 \mathrm{~mm}$ connected in parallel (Figure 2).

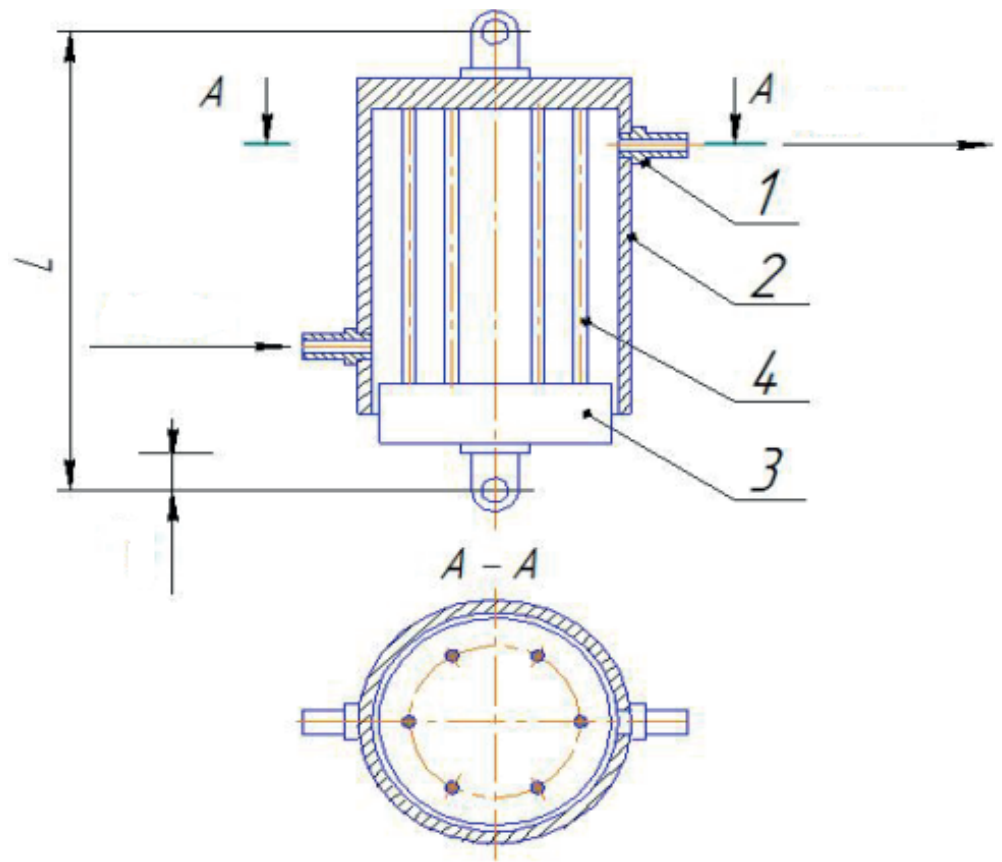

Figure 2: Multi-link actuator with parallel arrangement of power elements 1- connecting pipe; 2- body; 3-plate; 4-power elements.

In this case the total force developed by the actuator, in general, must be summed in accordance with the number of the power elements. The authors confirmed this assumption experimentally. For example, for one power element the developed stress at zero displacement is $280-320 \mathrm{MPa}$ whereas for the actuator from three thermally 
thin elements it is 850-950 MPa [9]. Authors of the work [10], where rod elements were used, came to the same conclusion.

Advantages of the multi-link actuators consisting of thermally thin elements are:

- uniform heating across length and cross section is ensured;

- inducing of memory in a single element does not require equipment with high specific pressures;

- supply of coolant and removal of heat are facilitated, for example, heating - by passing a current through the wires, removal of heat - by blowing up of the wires by air;

- the possibility appears for creation of actuators with a significant deforming force.

\section{MATERIALS AND METHODS}

The measuring stand was designed and fabricated to obtain technical and operational characteristics of a power element (Figure 3).

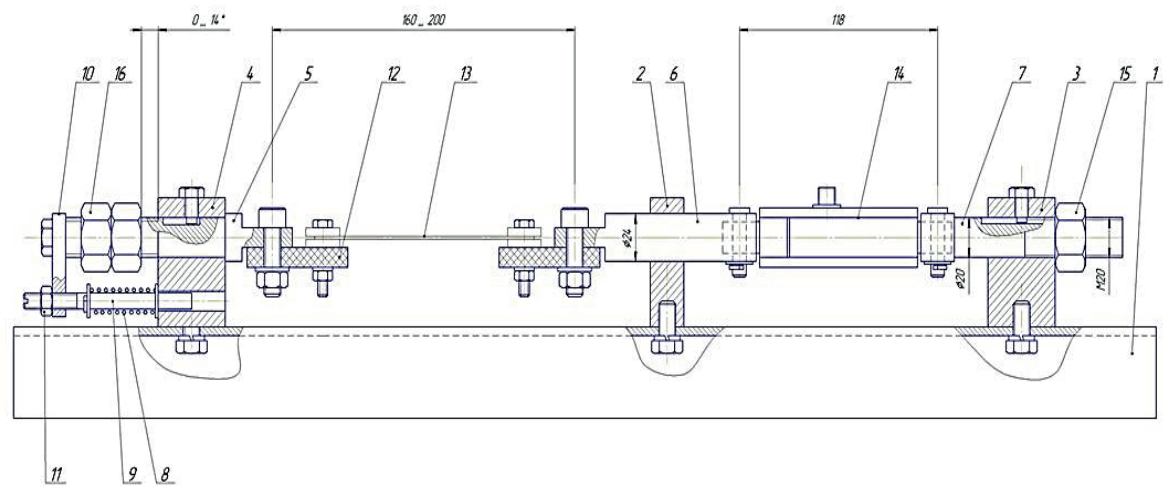

Figure 3: Scheme for testing of wire power elements.

The special device (stand) was designed for performance of tests and definition of main technical parameters. Its scheme is shown in Figure 3. The stand is the frame on which are placed blocks of fastening of the power element, the mechanical stretching device, current leads, units of measuring of force and temperature.

On the base 1 three supports 2, 3, 4 are fixed rigidly and coaxially relative to each other, in the guide holes of which the holder 5 , holder-adapter 6 and tension rod 7 are mounted with the possibility of easy axial displacement. The holder 5 is pressed against the support 4 by the spring 8 , the force of compression of which is adjustable by screwing the stud 9 into the boss10 which is fastened rigidly on the holder and is 
fixed by the lock nut 11. The compression force of the spring is set in accordance with the test program, and is $7-12 \%$ of the expected force in the manifestation of "shape memory" of the test sample.

The test sample 13 is fastened in the bosses of the holders 5 and 6 on special insulating adapters 12, the electronic force gauge 14 is installed between the adapter 6 and rod 7. Readings of the gauge 14 are recorded with an oscilloscope. Pre-tension of the power element, equal to the compression force of the spring, is performed by the nut 15 .

The stretching device has a stop limiting the displacement of the power element when restoring "shape memory".

\section{RESULTS AND DISCUSSION}

In the experiment the temperature of reverse martensitic transformation $T_{M}$ was prescribed equal to $100{ }^{\circ} \mathrm{C}$. This temperature determined the magnitude and duration of the passing current.

In the experiment the wires $\varnothing 1.0 \mathrm{~mm}$ from the alloy $\mathrm{TH}_{1}$ [11] of working length $l_{p a 6}=100 M M$ were used

Changing the degree of deformation by limiting of displacement with the help of the stop of the stretching device, we recorded the forces, developed therewith (Figure 4).

a) at displacement of $0 \mathrm{~mm}$

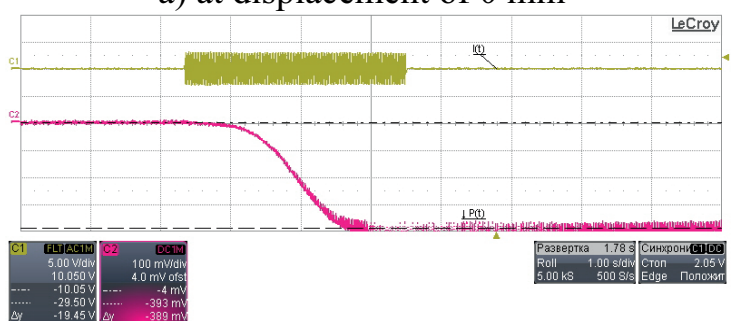

б) at displacement of $1,5 \mathrm{~mm}$

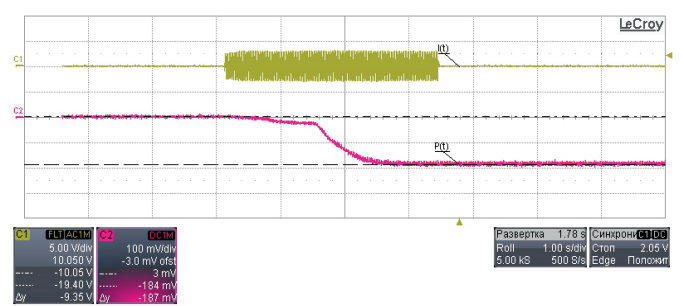

в) at displacement of $3 \mathrm{~mm}$

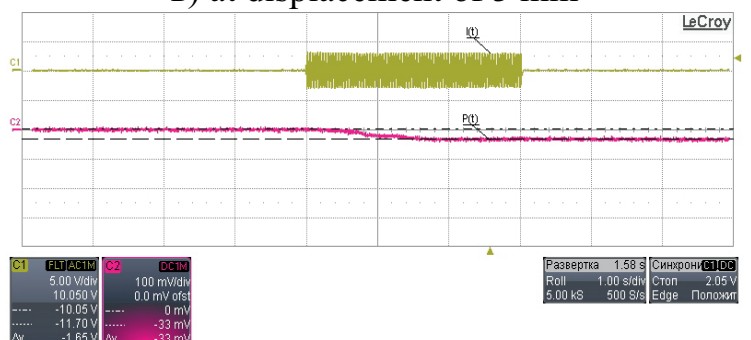

Figure 4: Deformation-force graphics with different displacements. 
Processing of results of the experiments, presented in Fig.4, made it possible to obtain the deformation-force characteristic of the power element (Fig. 5) which allowed defining design parameters, geometric sizes (characteristics) of the actuator as a whole, including the required number of power elements as well as the developed forces at the predetermined (required) displacement.

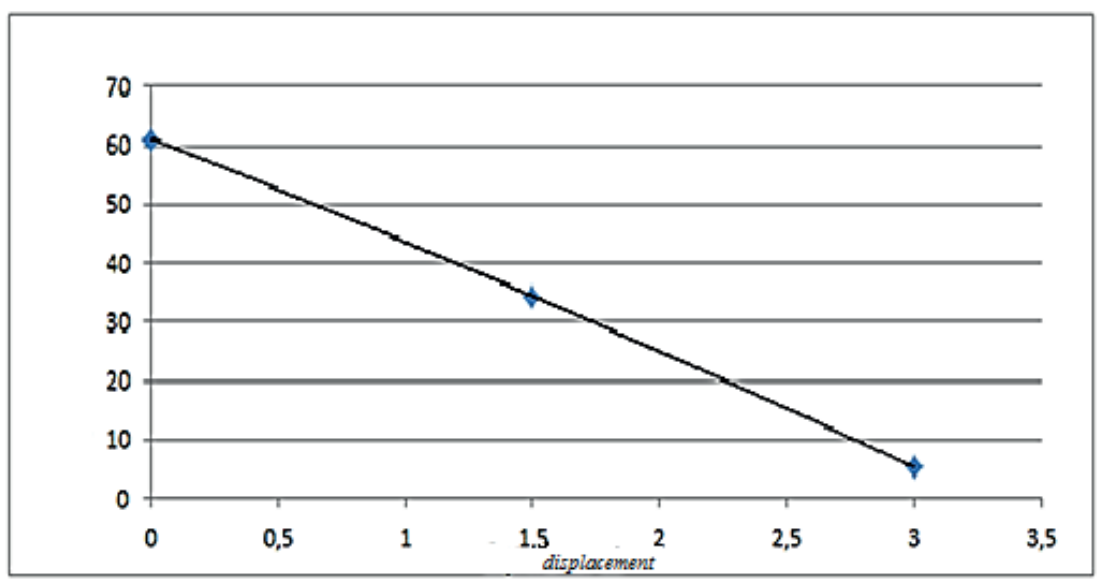

Figure 5: Graph of the dependence of developed stresses on the magnitude of displacement.

Moreover, the obtained graphs made it possible to evaluate the high-speed response of the power element depending on the speed of its heating. The heating speed was varied by changing the magnitude of current flowing through the wire I = $20,30 \mathrm{~A}$ and with a corresponding decrease in time of heating up to $100^{\circ} \mathrm{C}$. Results of such processing of the experiments are presented in Table 1 and make it possible (by selecting the magnitude of current I) to provide the predetermined productivity of the devices with the cyclic use of them.

TABLE 1: Varying the speed of build-up of load from the heating speed.
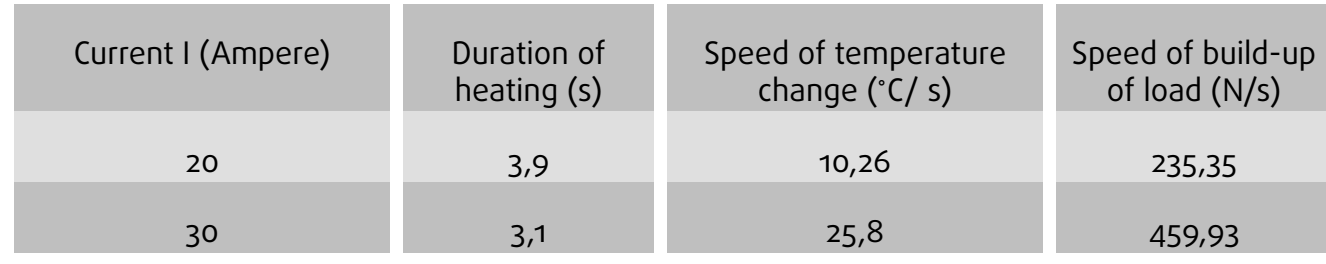

Using the obtained data, the actuator (Figure 6) was designed and fabricated for the model of the press with force of 7.060788 (kN) (Figure 7).

\section{CONCLUSIONS}

1. The new design of multi-link actuators which consists of thermally thin power elements connected in parallel has been presented. 


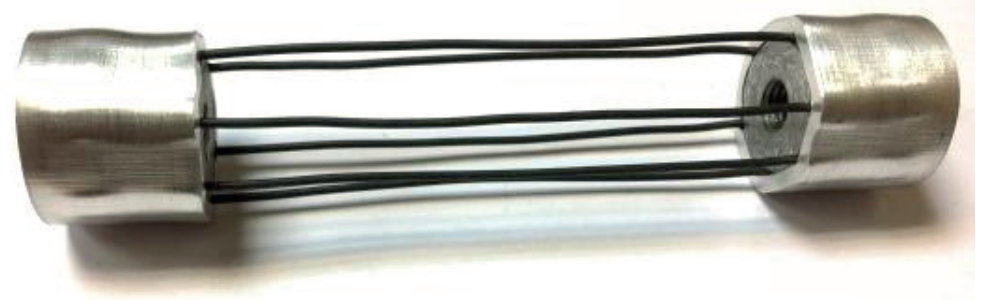

Figure 6: Multi-link actuator from the shape-memory material.

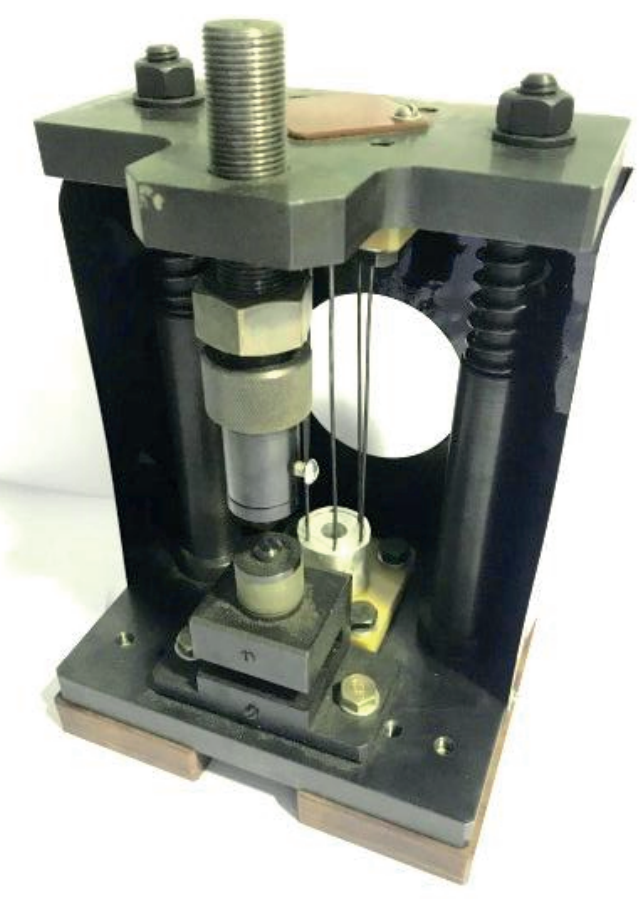

Figure 7: Press with the multi-link actuator.

2. Studies have been conducted which allow obtaining of initial data for designing a multi-link actuator (developing forces at the predetermined displacement, geometric sizes of the power element, number of power elements, length of the actuator, actuator productivity, a mode (speed) of heating and cooling).

3. The press has been tested in laboratory conditions and meets the technical specifications. 


\section{References}

[1] Tikhonov A.S. Application of the effect of memory of shape in modern mechanical engineering. Moscow, Mechanical Engineering, 1981, 76 pages.

[2] Belousov V.P., Dukin E.P., Favstov Ju.K. Re-usable servo mechanism with reciprocal motion/ Materials with the effect of shape memory and their application: Materials of the seminar, Novgorod, 1989

[3] Muslov S. A., Andreev V. A., Bondarev A. B., Sukhachev P. Y. M., Sverhslozhnye alloys with shape memory effect in science, engineering and medicine. The reference publication./ Publishing house "Folium". 2010. 456.

[4] Belyaev, S. P. Functional properties of Nickel-titanium under complex physical and mechanical effects Diss. doctor of physic-mechanical Sciences: SPb., 2012. - 279 c.

[5] Wei Z.G., Sandström R., Miyazaki S. Review. Shape memory materials and hybrid composites for smart systems. Part I. Shape memory materials. Part II. Shape memory hybrid composites // Journal of Materials Science. - 1998. - Vol. 33. - pp. 3743-3783.

[6] Gluschenkov V., Yusupov R., Alekhina V., Yuri E. Actuator from a material with the high-temperature shape memory effect and examples of its application in engineering // Key Engineering Materials, 2016. Vol. 684. Pp. 523-529

[7] Khusainov M. A. //Mechanical behavior of the alloy with shape memory and their use in the technique //Andreev V. A., Afanas'ev A. B. //Bulletin of the Novgorod state University.- 2005. - No. 30. - S. 1-11.

[8] Glushenkov V.A., Feoktistov V.S., Samsonov V.G., etc. Patent of the RF №1224179. Thermal press stamp.

[9] Glushenkov V. A., Yusupov R. Yu., Alekhina V. K., Egorov Yu. a. Electro-thermal actuator: patent of RF No. 172360; received 18.07.2017.

[10] Ilin A. A., Kolerov M. Y. Sharonov, A. A., Chernov, D. B., and Minaev, D. C.. Thermomechanical device of actuators. RF patent №2485198 received 20.06.2013

[11] Alekhine V. K., V. A. Glushenkov multi-link saleprivate from a material with shape memory and their characteristics // proceedings of the Samara scientific center of RAS. 2017. Vol. 19. No. 1 (3). P. $483-488$ 